\title{
Is it possible to identify individuals with mild cognitive impairment and Alzheimer's disease using a 30-minute neuropsychological battery?
}

\section{É possível identificar indivíduos com comprometimento cognitivo leve e doença de Alzheimer usando uma bateria neuropsicológica de 30 minutos?}

\author{
Gabriel Coutinho1,2, Ricardo de Oliveira-Souza1,3, Jorge Moll¹, Fernanda Tovar-Moll ${ }^{1,2}$, Paulo Mattosi,2 \\ 1 D'Or Institute for Research and Education (IDOR), Rio de Janeiro, RJ, Brazil. \\ 2 Institute of Biomedical Sciences, Federal University of Rio de Janeiro (UFRJ), Rio de Janeiro, RJ, Brazil. \\ ${ }^{3}$ Federal University of the State of Rio de Janeiro (UNI-Rio), Rio de Janeiro, RJ, Brazil.
}

This work was developed at D'Or Institute for Research and Education.

Received: 12/3/2012 - Accepted: 4/4/2013

\begin{abstract}
Background: Distinguishing individuals with dementia from those with mild cognitive impairment (MCI) might demand a neuropsychological evaluation. Methods: One hundred and thirty-one consecutive referred elderly patients (37 clinical-controls, 41 with amnestic MCI and 53 with possible/probable AD) were diagnosed with a comprehensive (full) neuropsychological battery, MRI and clinical data. All of the results were blindly coded and evaluated latter with a subset of the tests to reclassify the subjects as MCI, dementia or clinical-control. Agreement rates between both batteries were calculated. We also used ROC curves to establish the sensitivity and specificity of the brief battery for discriminating (i) clinical-control individuals from a group dementia and MCI patients; (ii) individuals with dementia from individuals without dementia; (iii) clinical-control individuals from a group of MCI. We compared performance of the three groups on all full battery tasks. Results: All neuropsychological tests showed differences between clinical-control and dementia groups. The comparison between MCI and the other groups mainly showed memory differences. Agreement between brief and full batteries was substantial (kappa $=0.805)$. Analyses with ROC curves showed good sensitivity and specificity to discriminate non-demented (clinical control plus MCI groups) and AD group and also to discriminate clinical-control individuals from individuals with cognitive decline (MCI plus AD group). However, sensitivity and specificity significantly decreased when brief battery was tested to discriminate only normal and MCI diagnosis. Discussion: The use of a brief battery might not be indicated to discriminate MCI and clinical-control individuals, but its use might be adequate to discriminate less specific groups (demented versus non-demented and pathological [dementia and $\mathrm{MCI}$ ] and non-pathological [clinical-control] groups).
\end{abstract}

Coutinho G, et al. / Rev Psiq Clín. 2013;40(4):139-43

Keywords: Alzheimer’s disease, cognitive assessment, dementia, memory, mild cognitive impairment.

\section{Resumo}

Contexto: A diferenciação de pacientes com diagnósticos de demência e de comprometimento cognitivo leve (CCL) pode exigir avaliação neuropsicológica. Métodos: Cento e trinta e um pacientes idosos consecutivos referidos para avaliação (37 controles-clínicos, 41 com CCL amnéstico e 53 com DA possível/ provável) foram diagnosticados com bateria neuropsicológica completa, RM e dados clínicos. Todos os resultados foram codificados de forma cega e posteriormente avaliados com parte dos testes para reclassificar indivíduos com CCL, demência ou controles-clínicos. Concordância entre as baterias foi calculada. Utilizamos curvas ROC para estabelecer sensibilidade e especificidade da bateria breve para discriminar: (i) controles-clínicos de um grupo de demência e CCL; (ii) indivíduos com demência daqueles indivíduos sem demência; (iii) controles clínicos daqueles indivíduos com diagnóstico de CCL. Comparamos o desempenho dos três grupos em todas as tarefas da bateria completa. Resultados: Todos os testes neuropsicológicos mostraram diferenças entre controles-clínicos e grupo de demência. A comparação entre CCL e outros grupos mostrou, principalmente, diferenças em tarefas de memória. Concordância entre baterias breve e completa foi substancial (kappa $=0.805$ ). Análises com curvas ROC demonstraram boas sensibilidade e especificidade quando comparados grupos de indivíduos com demência e sem demência (grupos de CCL e DA agrupados) e grupos de controle-clínico de indivíduos com declínio cognitivo (CCL associado à DA). Por outro lado, sensibilidade e especificidade diminuíram consideravelmente para discriminar controles-clínicos de indivíduos com diagnóstico de CCL. Conclusão: O uso de bateria breve pode não ser recomendado para discriminar controles-clínicos de indivíduos com CCL, porém o uso pode estar indicado para diferenciar grupos de especificidade menor [demência versus não demência ou grupos patológicos (demência e CCL) de grupo não patológicos (controles clínicos)].

Coutinho G, et al. / Rev Psiq Clín. 2013;40(4):139-43

Palavras-chave: Doença de Alzheimer, avaliação cognitiva, demência, memória, comprometimento cognitivo leve.

\section{Introduction}

Many studies of mild cognitive impairment (MCI) in the last decade have sought to elucidate clinical, neuropsychological and neuroimaging aspects ${ }^{1}$. MCI diagnosis is associated with elevated rates of conversion to $\mathrm{AD}^{2}$. The use of screening tests only, such as the MMSE, is not recommended due to the lack of specificity, sensitivity, or both ${ }^{3}$. To identify individuals at risk for Alzheimer's disease $(\mathrm{AD})$ or other dementias, appropriate neuropsychological tools to detect MCI are needed. There is no consensus, however, on which tests should be part of such an evaluation. It should also be considered that early treatment with cholinesterase inhibitors may benefit MCI individuals ${ }^{4}$. 
Most studies focus on the amnestic subtype of MCI, single or multiple-domain 5 , as the best predictor of $\mathrm{AD}$, which is the most prevalent dementia in the elderly ${ }^{6}$, which associate with significant impact even in initial in mild phase ${ }^{7}$. It should be noted that there is no consensus on the definition of impairment in non-memory functions, an aspect that may jeopardize the recognition of non-amnestic MCI.

Some studies in Brazil have proposed new neuropsychological batteries and brief screening tools for the diagnosis of both MCI and dementia ${ }^{8-11}$. Some studies have investigated single tests or existing batteries, such as the Clock Drawing Test (CDT) ${ }^{12}$, the Mini-Mental State Examination (MMSE) and the Cambridge Mental Disorders of the Elderly Examination (CAMDEX). Diniz et al. ${ }^{9}$ compared a brief screening and a neuropsychological battery, demonstrating that both could discriminate MCI from dementia (although they failed to discriminate among different types of MCI). Using a different design, Paula et al. ${ }^{13}$ evaluated a brief screening for a geriatric population that used tasks considered fast and easy to administrate. That study demonstrated the importance of evaluating cognition in elderly populations using batteries with good construction and valid criteria. Ladeira et al. ${ }^{14}$ showed that a combination of screening tools, such as the MMSE, verbal fluency and CDT, was not useful for identifying cases of AD or MCI.

The studies conducted by both Paula et al..$^{13}$ and Ladeira et al. ${ }^{14} \mathrm{did}$ not include memory tasks. Diniz et al. ${ }^{9}$ included a very short memory task that did not evaluate either retention over time or delayed recall. The use of batteries without memory tasks - or without memory tasks evaluating retention over time - has a greater likelihood of failure in identifying cases of amnestic MCI (single domain) where memory deficits are not accompanied by other cognitive impairments.

Comprehensive neuropsychological batteries have the obvious advantage of greater sensitivity to brain injury or dysfunction of any etiology, but at the expense of time and cost. Shorter batteries might also prove useful for research purposes and, to some extent, for clinical practice as well, particularly where a full neuropsychological examination is not immediately available or feasible. The need for consensus on a diagnostic battery for MCI motivated the current study. We aimed to develop a brief neuropsychological battery (lasting up to 30 minutes) to discriminate among normal aging, MCI and dementia. Based on the literature review, we hypothesized that a 30-minute battery would be suitable to discriminate the three groups with good sensitivity and specificity.

\section{Methods}

One hundred and thirty-one elderly patients (37 controls, $41 \mathrm{MCI}$ and 53 possible or probable $\mathrm{AD}$ ) were consecutively referred for neuropsychological evaluation in a private clinic. All patients were referred by their physicians because of memory complaints to discriminate among normal aging, MCI or dementia. The demographic profile of the patients is shown in table 1 . This study was approved by the Ethics Committee of D'Or Institute for Research and Education; being a retrospective survey of clinical files, patients did not sign an informed consent, in accordance to Brazilian regulations.

Categorical ("golden standard") diagnoses. Diagnoses were made by consensus by a trained, board-certified neuropsychologist (GC) and a board-certified psychiatrist (PM), considering DSM-IV criteria, neuroimaging (MRI), clinical data and the neuropsychological results from the full battery. $\mathrm{AD}$ diagnoses were made based on NINCDS-ADRDA criteria ${ }^{15}$. MCI diagnoses were made according to the definitions proposed by Winblad et al. ${ }^{16}$, but restricted to amnestic subtype, since we aimed to study individuals at higher risks of developing $\mathrm{AD}$ : memory complaints; not demented but also not normal for age; cognitive decline; essentially normal functional activities of daily living. The classification of MCI was determined by a consensus by the aforementioned researchers (PM and GC) based on clinical data and neuropsychological results from the full battery. After clinical data were collected (present complaints, collateral reports, premorbid history, family history, medication), all individuals underwent a comprehensive evaluation that included the following test battery: Logical Memory from WMS-III, the Brazilian version of RAVLT17-18, Family Pictures, Digit Span, Spatial Span, CDT, MMSE, Vocabulary from WAIS-III, Matrix Reasoning from WAIS-III, and verbal fluency, both semantic (animals and fruits) and letter (F, A, and S). Participants were also evaluated with the Geriatric Depression Scale (GDS) ${ }^{19}$ and the Memory Assessment Complaints Questionnaire (MAC-Q) ${ }^{20}$. Daily activities were investigated with Pfeffer Functional Activities Questionnaire ${ }^{21}$. The questionnaire was filled out by a close relative or caregiver.

Brief neuropsychological battery. The results for all patients were blindly coded and evaluated a second time with a subset of the tests used in the full battery. The results of performance on the brief battery were used to make a categorical diagnosis of "normal", "MCI", or "dementia" based on the judgment of the authors who determined categorical diagnoses. In this step, the clinicians only considered neuropsychological results. The diagnoses generated by a brief battery were then compared to the golden standard diagnoses, as explained above. The tests in the brief battery were chosen based on the following criteria: a) a short time should be required to administer the tasks; b) there should be extensive neuropsychological data in the literature about the test structure and its interpretation; c) there should be normative data for each test - it must be highlighted that some of the used tasks do not have available Brazilian normative groups; d) there should be a memory task that evaluate both immediate and delayed recall, but other cognitive domains should be covered as well; and e) the tests should be either the ones used in the original MCI studies or structurally equivalent to them. The following tests complied with these criteria: the verbal memory task from the original MCI studies (i.e., Logical Memory from $\mathrm{WMS}^{22}$ ), the semantic (animals) fluency test, the auditory working memory test (Digit Span, comprising measures of the phonological loop and central executive functions), constructional praxis and executive functioning (CDT), and the MMSE. Tests of brief and full battery are listed in table 2 .

Agreement rates between the full (comprehensive) and brief batteries were calculated with the kappa statistics with quadratic weighting by considering three categorical diagnoses (dementia, MCI, and normal). Two analyses were then performed, both comparing the brief and the comprehensive batteries, but considering only two groups for each analysis (described below). These analyses used ROC curves to establish the sensitivity and specificity of the brief battery in discriminating (i) normal individuals from a group of demented and MCI patients (i.e., "normal" versus "pathologic"; (ii) individuals with dementia from individuals without dementia, the latter group comprising normal and MCI subjects; and (iii) normal individuals from MCI group. We also compared the performance of the three

Table 1. Demographic variables across diagnostic (gold standard) categories

\begin{tabular}{|l|c|c|c|c|c|}
\hline & $\mathrm{AD}$ & $\mathrm{MCl}$ & Controls & & Contrasts \\
\hline $\mathrm{N}$ & 53 & 41 & 37 & & \\
\hline Age (years) & $75.25( \pm 7.41)$ & $73.76( \pm 7.01)$ & $72.08( \pm 6.86)$ & $\mathrm{P}=0.120$ & $1=2=3$ \\
\hline Gender (women/men) & $30 / 23$ & $23 / 18$ & $28 / 9$ & $\mathrm{P}=0.123$ & \\
\hline Education (years) & $10.88( \pm 4.5)$ & $13.02( \pm 4.13)$ & $14.56( \pm 5.25)$ & $\mathrm{P}=0.003$ & $3>1 ; 3>2 ; 1=2$ \\
\hline
\end{tabular}

Statistical analysis: Age - One-way ANOVA with post-hoc Bonferroni test. Gender - Pearson chi-Square. Education - Kruskal-Wallis test. 
Table 2. Tests from the full and brief battery

\begin{tabular}{|l|l|}
\hline \multicolumn{1}{|c|}{ Full battery } & \multicolumn{1}{c|}{ Brief battery } \\
\hline Logical Memory & Logical Memory \\
\hline Clock Drawing Test & Clock Drawing Test \\
\hline Digit Span & Digit Span \\
\hline Fluency Animals & Fluency Animals \\
\hline Fluency Fruits & MEEM \\
\hline Fluency F & \\
\hline Fluency A & \\
\hline Fluency S & \\
\hline MEEM & \\
\hline RAVLT & \\
\hline Family Pictures & \\
\hline Vocabulary & \\
\hline Matrix & \\
\hline
\end{tabular}

groups on all tasks of the full battery. Because most measures did not have a normal distribution, comparisons were performed using the Kruskal-Wallis test, and contrasts were performed using the Mann-Whitney with the post-hoc Bonferroni test. Comparisons of age were made with ANOVA, and the Kruskal-Wallis test was used for comparisons of educational level. The gender distribution was calculated with Pearson's chi-square test $\left(\chi^{2}\right)$.

\section{Results}

The three groups did not differ in age. The normal group had more years of education than the AD group $(p=0.003)$, but the normal and MCI groups did not differ in terms of education. Gender distribution did not differ across groups. The $\mathrm{AD}$ group comprised 53 individuals, whereas the MCI and control groups comprised 41 and 37 individuals, respectively. The results are summarized in table 1 .

All neuropsychological tests showed significant differences between the normal and $\mathrm{AD}$ groups. When comparing the normal and MCI groups, memory tests (RAVLT A1, RAVLT A5, Family Pictures and Logical Memory [both immediate and delayed recall]), MEEM and semantic verbal fluency (a animals and fruits) reached significance. When comparing the MCI and AD groups, only the forward Digit Span did not reach significance. The results of the comparisons are summarized in table 3.
We also assessed the combination of the tests used to compose the brief battery. The agreement between the full battery and the brief battery was considered substantial (kappa $=0.805$ ) according to the reliability patterns proposed by Shrout and Fleiss ${ }^{23}$. When the MCI and $\mathrm{AD}$ cases were sorted in the same group, the brief battery had good sensitivity (78.4\%) and specificity (89.4\%) for discriminating patients (MCI plus AD) from normal cases [area under the curve $(\mathrm{AUC})=0.84]$. The positive and negative predictive values were $74.4 \%$ and $91.3 \%$, respectively. When the MCI and normal cases were sorted in the same group, the brief battery had good sensitivity $(83.3 \%)$ and specificity $(90.6 \%)$ for discriminating non-demented (MCI plus normal) from $\mathrm{AD}$ patients ( $\mathrm{AUC}=0.87$ ). The positive and negative predictive values were $92.9 \%$ and $78.7 \%$, respectively. We performed an additional analysis, this time comparing only MCI and normal groups - excluding all individuals that received a diagnosis of $\mathrm{AD}$ from either battery -; the comparisons were made considering 28 MCI and 37 normal individuals. In this case, both sensitivity and specificity decreased (64.28\% and 78.37\%, respectively; AUC $=0.71$ ). The positive and negative predictive values were $69.2 \%$ and $74.4 \%$, respectively.

\section{Discussion}

Normal individuals had more years of education in comparison to the other groups, a result previously identified in other studies ${ }^{6}$. The groups did not differ in terms of age (Table 1) or gender distribution The latter two findings are not in accordance with the findings of other studies, which highlight age and gender (female) as two of the most important risk factors for developing $\mathrm{AD}^{24}$. This discrepancy may be secondary to a referral bias because we evaluated a sample of patients referred to a private unit for neuropsychological evaluation of memory problems, which occur in a wider age range of individuals in clinical practice, from adulthood to old age.

Most of the studies on MCI have considered only amnestic subtypes, including both single and multiple domains ${ }^{25}$. The study conducted by Diniz et al. ${ }^{9}$ found that amnestic subtypes of MCI were the most common in their sample, corresponding to approximately two-thirds of MCI cases. One possible explanation is that AD is the most common type of dementia; thus, samples comprising individuals with cognitive decline without dementia are expected to include primarily amnestic subtypes of MCI. For this reason, we developed a brief battery that used an episodic memory task allowing us to assess immediate and delayed recall. Therefore, our MCI individuals are amnestic (both single and multiple domains).

Table 3. Neuropsychological measures and mean results

\begin{tabular}{|c|c|c|c|c|c|}
\hline & $\begin{array}{c}\text { Normal } \\
\mathrm{N}=37(28.2 \%)\end{array}$ & $\begin{array}{c}\mathrm{MCl} \\
\mathrm{N}=41(31.2 \%)\end{array}$ & $\begin{array}{c}A D \\
N=53(40.6 \%)\end{array}$ & $\mathrm{H}$ & Contrasts \\
\hline Logical Memory 1 & $33.05 \pm 9.42$ & $23.56 \pm 8.68$ & $13.64 \pm 7.47$ & $61.80^{*}$ & $1>2>3$ \\
\hline Logical Memory 2 & $21.00 \pm 6.55$ & $11.03 \pm 4.06$ & $4.80 \pm 5.94$ & $81.87^{*}$ & $1>2>3$ \\
\hline Clock Test & $9.70 \pm 1.13$ & $9.05 \pm 2.14$ & $8.00 \pm 2.87$ & $16.35^{*}$ & $1=2>3$ \\
\hline Span F & $5.27 \pm 0.99$ & $5.31 \pm 1.27$ & $4.83 \pm 0.89$ & 6.78 & $1=2=3$ \\
\hline Span B & $3.94 \pm 1.05$ & $3.92 \pm 1.12$ & $3.22 \pm 0.80$ & $15.45^{*}$ & $1=2>3$ \\
\hline Fluency Ani & $16.62 \pm 4.38$ & $13.24 \pm 4.28$ & $9.30 \pm 4.13$ & $48.93^{*}$ & $1>2>3$ \\
\hline Fluency Fru & $14.75 \pm 4.34$ & $12.09 \pm 3.62$ & $9.28 \pm 3.19$ & $38.51^{*}$ & $1>2>3$ \\
\hline Fluency F & $12.35 \pm 5.05$ & $11.95 \pm 5.51$ & $7.52 \pm 3.89$ & $25.59^{*}$ & $1=2>3$ \\
\hline Fluency A & $10.78 \pm 4.09$ & $11.73 \pm 5.46$ & $6.66 \pm 3.74$ & $29.67^{*}$ & $1=2>3$ \\
\hline Fluency S & $11.48 \pm 4.70$ & $10.70 \pm 4.58$ & $7.57 \pm 4.15$ & $18.01^{*}$ & $1=2>3$ \\
\hline MEEM & $27.16 \pm 1.80$ & $25.53 \pm 2.14$ & $21.64 \pm 3.75$ & $61.05^{*}$ & $1>2>3$ \\
\hline RAVLT A1 & $5.40 \pm 1.78$ & $4.29 \pm 1.27$ & $3.20 \pm 1.58$ & $29.67^{*}$ & $1>2>3$ \\
\hline RAVLT A5 & $11.16 \pm 2.10$ & $8.63 \pm 1.95$ & $6.32 \pm 2.25$ & $61.98^{*}$ & $1>2>3$ \\
\hline RAVLT A7/A6 & $1.09 \pm 0.27$ & $0.94 \pm 0.51$ & $0.70 \pm 0.79$ & $19.22^{*}$ & $1=2>3$ \\
\hline RAVLT R & $11.08 \pm 4.11$ & $7.27 \pm 6.49$ & $1.79 \pm 8.07$ & $34.31^{*}$ & $1=2>3$ \\
\hline Family Pictures 1 & $28.46 \pm 10.88$ & $15.78 \pm 9.31$ & $13.49 \pm 6.40$ & $38.23^{*}$ & $1>2>3$ \\
\hline Family Pictures 2 & $27.27 \pm 9.38$ & $15.85 \pm 9.30$ & $13.13 \pm 7.13$ & $41.99^{*}$ & $1>2>3$ \\
\hline Vocabulary & $43.84 \pm 8.90$ & $40.00 \pm 11.75$ & $32.19 \pm 13.16$ & $19.09^{*}$ & $1=2>3$ \\
\hline Matrix & $11.67 \pm 5.20$ & $10.63 \pm 5.91$ & $6.45 \pm 3.68$ & $28.11^{*}$ & $1=2>3$ \\
\hline
\end{tabular}

${ }^{*}$ p-values $\leq 0.05$, two-tailed contrast was performed using the Mann-Whitney (with post-hoc Bonferroni) test. 
The performances in the three groups showed discrepancies in most of the measures, except for the Digit Span and the CDT. Despite its failure to discriminate normal individuals from MCI individuals, the CDT discriminated MCI from $\mathrm{AD}$. This result could be explained by the fact that CDT is a task that aims to evaluate executive functions and constructional praxis, which are not expected to be impaired in the amnestic forms of $\mathrm{MCI}$ but are often impaired in $\mathrm{AD}^{12}$. In addition, the CDT is often used to support an AD diagnosis in the literature. We found it to be important even though it does not help to discriminate normal individuals from those with MCI.

Digit Span forward performances did not differ among the three groups, indicating that there were no differences in the phonological loop. In fact, Digit Span does not process semantic information ${ }^{26}$ and is generally intact at the preclinical and early stages of $\mathrm{AD}^{27}$. Performances on the Digit Span backward (the second step of the Digit Span, in which digits are repeated in the reverse order) were similar in comparisons of normal and MCI individuals, whereas individuals with $\mathrm{AD}$ were significantly impaired compared to the non-demented groups. The Digit Span test is a measure of central executive function ${ }^{26}$; it is expected that amnestic type (single domain) of MCI do not involve difficulties with this function.

All of the other measures of the brief battery (i.e., Logical Memory I and II, verbal fluency (animals), and MMSE) were significantly different between normal and MCI patients as well as between MCI and AD patients.

We also performed a post-hoc analysis of the tests used to compose the brief battery. The agreement between full and brief batteries had a kappa of 0.805 . This finding suggests that, at least for samples including individuals with cognitive decline marked by memory deficits, the brief battery might be applied. When grouping MCI and AD cases in the same group and comparing the sensitivity and specificity of the brief battery in discriminating those groups, we found good sensitivity and specificity $(78.38 \%$ and $89.36 \%$, respectively). The AUC was 0.839 , suggesting that this brief battery might also be useful in discriminating normal and pathological aging. When grouping $\mathrm{MCI}$ and normal individuals in the same group and comparing their performance to that of AD individuals, we found good sensitivity and specificity $(83.33 \%$ and $90.57 \%$, respectively), suggesting that this battery might be useful to discriminate individuals with $\mathrm{AD}$ from normal individuals.

Contrarily to our expectations, both sensitivity and specificity of brief battery significantly decreased $(64.28 \%$ and $78.37 \%$, respectively) when we compared only groups of MCI and normal individuals. Additionally, positive and negative predictive values were $69.2 \%$ and $74.4 \%$, respectively, which indicates that this brief battery might not be recommended to discriminate MCI and normal individuals.

Controversially to our results, another study conducted in Brazil $^{8}$ showed that brief batteries could accurately discriminate MCI from normal and demented individuals, although not sensitively enough to establish subtypes of MCI (e.g., amnestic, non-amnestic or multiple domain). Our findings suggest that, at least in a sample that mirror clinical everyday clinical practice (i.e., clinical-control individuals, MCI and individuals with dementia), the use of this brief battery should be restricted to the purpose of determining less specific groups, such as: 1) individuals with no decline versus individuals with cognitive decline (normal versus MCI plus AD); or 2) individuals without $\mathrm{AD}$ (MCI plus normal individuals) from individuals with $\mathrm{AD}$.

\section{Conclusion}

It should be stressed that the proposed brief battery alone does not provide an MCI diagnosis per se, which requires clinical evaluation by the physician. The use of a brief battery with both immediate and delayed recall might not be recommend for clinicians with the aim of discriminating MCI from normal aging. Furthermore, it should be noted that for the purposes of an individual evaluation, there is a paucity of adequate normative data in our country, which is well known for the enormous heterogeneity of the population in different regions. For this reason, we selected tests with normative data, extensive data, or both because future studies may provide specific norms for the proposed brief battery.

Despite good agreement rates between the full battery and the brief battery $(($ kappa $=0.805)$, several diagnoses using our gold standard changed when using the brief battery, which is critical from the perspective of individual cases. For example, $13 \mathrm{MCI}$ subjects were incorrectly classified as having dementia, whereas 5 individuals with dementia were reclassified as MCI.

The brief battery demonstrated good sensitivity and specificity for two specific purposes: 1) the discrimination of individuals without significant cognitive decline versus individuals with significant cognitive decline (normal versus MCI plus AD); and 2) the discrimination of $\mathrm{AD}$ from non-AD groups (MCI plus normal individuals).

\section{Limitations}

This study should be understood in light of some limitations. Our dementia group could be heterogeneous regarding the severity of the cognitive deficit because we used categorical diagnoses but not severity scales. Because our study was focused in individuals with memory complaints (following other studies comprising amnestic $\mathrm{MCI}$ ), we do not know whether our brief battery might be helpful in diagnosing non-amnestic MCI or non-Alzheimer dementias. For the same reason, the value of our brief battery in the ancillary diagnosis of dementias associated with behavioral changes or psychopathological symptoms remains to be demonstrated. Moreover, despite the good statistical agreement between both batteries, its use should be restricted to the aforementioned conditions.

\section{Acknowledgments}

We would like to thank Raphael Suwwan for his contribution with statistical analyses.

\section{References}

1. Perrin RJ, Fagan AM, Holtzman DM. Multimodal techniques for diagnosis and prognosis of Alzheimer's disease. Nature. 2009;461:916-22.

2. Hansson O, Zetterberg H, Buchhave P, Londos E, Blennow K, Minthon L. Association between CSF biomarkers and incipient Alzheimer's disease in patients with mild cognitive impairment: a follow-up study. Lancet Neurol. 2006;5:228-34.

3. Mitchell AJ. A meta-analysis of the accuracy of the mini-mental state examination in the detection of dementia and mild cognitive impairment. J Psychiatr Res. 2009;43:411-31.

4. Diniz B, Pinto Jr JA, Gonzaga MLC, Guimarães FM, Gattaz WF, Forlenza OV. To treat or not to treat? A meta-analysis of the use of cholinesterase inhibitors in mild cognitive impairment for delaying progression to Alzheimer's disease. Eur Arch Psychiatry Clin Neurosci. 2009;259:248-56.

5. Lonie JA, Tieney KM, Ebmeier KP. Screening for mild cognitive impairment: a systematic review. Int J Geriatr Psychiatry. 2009;24(9):902-15.

6. Nitrini R, Bottino CM, Albala C, Capunay NSC, Ketzoian C, Rodriguez JJL, et al. Prevalence of dementia in Latin America: a collaborative study of population-based cohorts. International Psychogeriatr. 2009;21(4):622-30.

7. Zidan M, Arcoverde C, Araújo N, Vasques P, Rios A, Laks J, et al. Motor and functional changes in different stages of Alzheimer's disease. Rev Psiq Clín. 2012;39(5):161-5.

8. Yassuda MS, Diniz BSO, Flaks MK, Viola LF, Pereira FS, Nunes PV, et al Neuropsychological profile of Brazilian older adults with heterogeneous educational backgrounds. Arch Clin Neuropsychol. 2009;24:71-9.

9. Diniz BS, Nunes PV, Yassuda MS, Pereira FS, Flaks MK, Viola LF, et al. Mild cognitive impairment: cognitive screening or neuropsychological assessment? Rev Bras Psiquiatr. 2008;30(4):316-21.

10. Diniz BS, Yassuda MS, Nunes PV, Radanovic M, Forlenza OV. Mini-mental State Examination performance in mild cognitive impairment subtypes. International Psychogeriatr. 2007;19(4):647-56. 
11. de Abreu ID, Nunes PV, Diniz BS, Forlenza OV. Combining functional scales and cognitive tests in screening for mild cognitive impairment at a university-based memory clinic in Brazil. Rev Bras Psiquiatr. 2008;30(4):346-9.

12. Lourenço RA, Ribeiro-Filho ST, Moreira IFH, Paradela EMP, de Miranda AS. The Clock Drawing Test: performance among elderly with low educational level. Rev Bras Psiquiatr. 2008;30(4):309-15.

13. Paula JJ, Shlottdeldt CG, Moreira L, Cotta M, Bicalho MA, Romano-Silva MA, et al. Psychometric properties of a brief neuropsychological protocol for use in geriatric populations. Rev Psiq Clín. 2010;7(6):246-50.

14. Ladeira RB, Diniz BS, Nunes PV, Forlenza OV. Combining cognitive screening tests for the evaluation of mild cognitive impairment in the elderly. Clinics. 2009;64:967-73.

15. McKhann G, Drachman D, Folstein M, Katzman R, Price D, Stadlan EM. Clinical diagnosis of Alzheimer disease: report of NINCDS-ADRDA Work Group under the auspices of Department of Health and Human Service Task Force on Alzheimer's Disease. Neurology. 1984;34(7):939-44.

16. Winblad B, Palmer K, Kivipelto M, Jelic V, Fratiglioni L, Wahlund L, et al. Mild cognitive impairment - beyond controversies, towards a consensus: report of the International Working Group on Mild Cognitive Impairment. J Int Med. 2004;256;240-6.

17. Malloy-Diniz LF, Lasmar VAP, Gazinelli LSR, Fuentes D, Salgado JV. The Rey Auditory-Verbal Learning Test: applicability for the Brazilian elderly population. Rev Bras Psiquiatr. 2007;29(4):324-9.
18. Paula JJ, Melo L, Nicolato R, Moraes E, Bicalho MA, Hamdan A, et al. Reliability and construct validity of the Rey-Auditory Verbal Learning Test in Brazilian elders. Rev Psiq Clín. 2012;39(1):19-23.

19. Yesavage JA, Brink TL, Rose TL, Lum O, Huang V, Adey M, et al. Development and validation of a geriatric depression screening scale: a preliminary report. J Psychiat Res. 1983;17:37-49.

20. Crook TH, Feher EP, Larabee GJ. Assessment of memory complaint in age-associated memory impairment: the MAC-Q. Int Psychogeriatr. 1992;4:165-75.

21. Pfeffer RI, Kurosaki TT, Harrah CH Jr, Chance JM, Filos S. Measurement functional activities in older adults in the community. J Gerontol. 1982;37(3):323-9.

22. Petersen RC, Smith GE, Waring SC, Ivnik RJ, Tangalos EG, Kokmen E. Mild cognitive impairment: clinical characterization and outcome. Arch Neurol. 1999;56:303-8.

23. Shrout PE, Fleiss JL. Intraclass correlations: uses in assessing rater reliability. Psychol Bull. 1979;86:420-8.

24. Jalbert JJ, Daiello LA, Lapane KL. Dementia of the Alzheimer type. Epidemiol Rev. 2008;30:15-34.

25. Mitchell AJ, Shiri-Feshki M. Rate of progression of mild cognitive impairment to dementia - meta-analysis of 41 robust inception cohort studies. Acta Psychiatr Scand. 2009;119:252-65.

26. Baddeley A. The episodic buffer: a new component of working memory. Trends Cogn Sci. 2000;4:417-23.

27. Huntley JD, Howard RJ. Working memory in early Alzheimer's disease: a neuropsychological review. Int J Psychiatry. 2010;25(2):121-32. 